\title{
Research on Intercultural Communication of Chinese Movies
}

\author{
Tianzhi Ren \\ Communication University of China, China, Beijing, 100024
}

Keywords: Intercultural Communication, Chinese Movies

\begin{abstract}
The study of intercultural communication in Chinese film faces a contradiction: on the one hand, starting from the scientific nature of the research results, it requires comprehensive analysis of various factors in the cross-cultural transmission of films; and on the other hand, from the operability of the research process in considering, it is difficult to carry out multi-layered diachronic and synchronic studies on multiple sites at the same time. Faced with this complex situation, based on culture, it is the foundation of the study of intercultural communication in Chinese film. Take the image expression as the starting point and the reference to the Hollywood movies in the United States contribute to the concreteness of intercultural communication research. The combination of quantitative and qualitative, the research method of the intersection of film theory and intercultural communication theory is the guarantee of the study of Chinese film intercultural communication from extensiveness to refinement.
\end{abstract}

\section{Introduction}

At present, due to the development of science and technology and the globalization of economy, "the interdependence and connection of the entire world is increasingly strengthened" [1]. Chinese movies are subject to the tide of globalization, and the cross-cultural communication problems they face are inevitable and urgent. As a leader in the global capitalist cultural transmission, Hollywood in the United States not only promotes, propagandizes and spreads Western mainstream culture and its values by virtue of its advantages in science and technology and its unequal cross-cultural communication order, but also through "malicious derogatory and devastating the history and culture of developing countries in an effort to make the history and culture of developing countries not discolored or faded or marginalized in the process of globalization [2] (P38). Facts have proved that the power of cultural discourse is becoming the foundation of a country's international status and development prospects. In this context, the cross-cultural communication of Chinese films has three levels of significance: First, economically, it is "the intrinsic requirement of itself as a cultural industry" [3] (P14); secondly, from the ideological point of view, it shoulders the heavy responsibility of promoting the right to speak Chinese culture. Thirdly, from a higher aspiration, it is to better promote understanding and exchange among different cultures.

\section{The Historical Review and Related Issues of Chinese Film Intercultural Communication}

The first real Chinese movie to enter the Hollywood market was the martial arts star Bruce Lee. In the early 1970s, he rushed to the world with his righteous awe-inspiring image, reinvented Chinese kung fu and added Kung Fu to English words. In the early 90s, China's fifth generation of directors made Chinese films appear in the western movie industry frequently. At the International Film Festivals (Venice, Cannes, Berlin, etc.), "Yellow Earth" and "Red Sorghum" attracted the attention of international film festivals. ), Chinese people have had great gains. Most notable is the "Family Trilogy" composed of Taiwanese Cenozoic directors Ang Lee, "Push Hands," "Wedding Banquet," and "Diet Men and Women." It infiltrates the spirit of traditional Chinese culture and pays more attention to exploring the eastern family ethics Affection and interpersonal relationship, and focus on analyzing and displaying the conflicts, oppositions, infiltrations and reconciliation 
between Chinese and Western cultures under the conditions of the new historical era and the ethical issues of ethics in a large cultural context. "[3] Cultural differences of interest and thinking, made both the good and the audience's effect. Since the new century, "Crouching Tiger, Hidden Dragon", "Hero", "Banquet", "Ambush" and "Lust Caution" have obtained the spread effect of "two incense in the wall" in intercultural communication. So far, there are 4 Chinese films in the top 10 U.S. box office films, with "Crouching Tiger, Hidden Dragon" and "Heroes" ranked first and third respectively. This shows that the film not only allows the Chinese people to understand the world, but also allows the world to understand China. At the dawn of the new century, the cross-cultural communication of Chinese films has drawn more and more attention. Chinese films provide good conditions for other audiences to understand Chinese culture. They have strong oriental cultural qualities, satisfy the aesthetic requirements of western audiences at different levels, and give them a strong interest in Chinese culture.

However, it has been very hard to understand and measure the "other" culture with the same standards that have long accustomed to Western-centered thinking and values as well as political prejudices. As a result, Western countries' perception of China remains at a very superficial stage. In the past, in our country's foreign cultural exchanges, the real acceptance by the international community was not the movie's true reflection of the essence of the Chinese culture. Westerners understood the film in terms of the surface language of the movie, causing many people in the western countries to mistakenly believe China is full of martial arts masters, and even think that China is still ignorant, poor and backward. When other countries' audiences enjoy the movie, understanding these as Chinese traditional culture not only fails to achieve the effect of intercultural communication, but will thicken the barriers to communication. And in Western films, the Chinese always play some image of incompetence, ignorance or evil. Although the situation in China has been somewhat improved in recent years, we can still see from the video Chinese image of the demonization and distortion. Such as the brutal and brutal Chinese triad groups in "Tomb Raider", the Chinese in the "war king" and the "indie paper" who were the initiators of the destruction of world peace. Chinese officials were ignorant images of being scared and mercenary, and from which we can see westerners' superficial understanding of Chinese and their prejudices. This shows not only that Westerners interpret Chinese culture and Chinese imagery from old concepts, but also that the influence of Chinese culture on the world is far different from that of Chinese culture itself. In an information-intensive society, various cultures are intertwined and spliced together, showing mixed cultural characteristics. If China wants to excel in the impact and integration of these diverse cultures, how to better cross-culture through the medium of film Exchange, reorienting the image of Chinese, more accurate Chinese culture to the world is the current have to think about.

\section{Chinese Film Intercultural Communication Strategy}

In the process of cultural transmission, ethnic things are often the most popular, India's song and dance, Chinese ink painting reputation worldwide, it is because it with a strong ethnic color. However, in the process of intercultural communication, there is a serious ecological crisis of cultural transmission. The continuous pressure of a strong culture, making the culture of weakness cannot highlight their cultural essence, and even the danger of being conquered by a strong culture. In the intercultural communication of our own culture, we can resist the invading of strong foreign cultures only by resolutely carrying forward the characteristics of our nation, which is also the historical mission of our films in intercultural communication. However, we must have a correct and profound understanding of the spirit of our own national culture. For example, there have been many films related to Chinese kung fu in Chinese films in recent years. After "Crouching Tiger, Hidden Dragon", "Heroes", "Promise", "Banquet Banquet" and "These films bring Chinese martial arts into the West, but the spirit of Chinese martial arts has not been well publicized. Most foreign viewers are still only at a stage of amazement about the Kung Fu in China. They cannot accurately understand the connotation of the Kung $\mathrm{Fu}$ in China, which often leads to failure in cultural exchanges. At this point, Korean movies can provide us with follow-up examples. South Korea's film and television over the past decade soared, rapidly set off a wave of "Korean Wave" in Asia, 
affecting many countries and regions around the world. It is inseparable from its perspective of intercultural communication that Korean movies can make such a remarkable achievement. They are based on tradition and convey traditional Confucian culture and family values through everyday real life scenes to show that modern society has a great influence on the traditional Impact and deconstruction, so that the audience personally feels South Korea's ethics and values of faith. It is encouraging that the movie "Huo Yuan Jia" has had a qualitative change in the Kung Fu movies. "Huo Yuanjia" shows the self-improvement of the Chinese nation's national spirit, taking morality as the human way, taking incapacity as a way of doing things and using the ever-changing ways of doing things. Confucianism, Taoism and Chineseized Buddhism passed through China Martial arts show up. Chinese cinema must dig out the true meaning of Chinese culture and spread the essence of Chinese culture while infecting the audience.

Commonness often resonates, making it easier for cultures to identify with each other. Therefore, a movie that is good at building a spiritual world of different cultural values, focusing on the world of themes and basic human emotions, tends to acquire the world more easily than a movie focusing on its own culture, focusing on regional themes and the feelings of a single nation Range of recognition. The more popular the movie, the more attention should be paid to the cross-cultural common human emotion and the commonalities between different cultures. The Japanese animated Spirited Away is a film by director Hayao Miyazaki dedicated to audiences who have been 10 years old and are about to enter the age of 10. The film tells the story of a Japanese girl's spiritual adventure, but the film is concerned about things common to humans --- growing up, the protagonist psychic experience is the world children have to face or jointly face the problem, The film won the seventy-fifth Academy Award for best animation, the fifty-second Berlin Film Festival Golden Bear Award, made an unprecedented strong reputation, which is the essential characteristics of the resonance of art can also be a Chinese film in the "culture output "process should learn and learn from the place. Human emotions are common, nothing less than affection, friendship, love, etc., the issue of human thinking is also common, including survival, death, life and so on. Although there are differences between Eastern and Western cultures, they are more or less similar on these issues and this should also be the focus of the Chinese film and television arts under the globalization context. Professor David Powell of the University of Wisconsin presented a paper entitled Transcultural Spaces: Chinese at the Second International Chinese Film Symposium in Hong Kong in 2000, Cinema as World Film, there is such a wonderful speech: "To put it bluntly, Chinese films belong to China, but they are also movies." However, as a powerful intercultural medium, cinema not only needs to rely on its own culture But also need to absorb a wider range of human civilizations, especially to share the fruits of other cultures, and only with the ability to absorb different cultures can Chinese films truly out of their borders and be accepted by audiences around the world. "' The more ethnic, the more the world is ". The world is expressed through ethnic cultures. The integration of the two allows us to re-read and think the world's propositions. Only by maintaining a cultural attitude of opening up and allowing nationalities and world sentiments to absorb each other can we create a brand new artistic perspective. Just as John Woo's "Face-changing Faces" succeeded, he said: "To film an international film, we must understand the local culture and their ideological behavior. However, the usual way I make films is to try to find out what we share in common. No matter where we come from or which ethnic group we come from, for example, Chinese people, whether from Hong Kong, Taiwan or the Mainland, we can find the common so-called 'benevolent spirit.' As for Westerners, I also hope to find out the difference between us They also have a kind of "benevolent spirit" and also like to help others, but the performance is not the same way, foreigners more subtle, Chinese are more arrogant in the "face" which I find a common point, that is, everyone Have a 'family concept. '

\section{Conclusion}

In the pattern of globalized communication, as a cultural carrier with special communication advantages, the function of cultural value communication in the process of cross-cultural communication is an important one and a symbol of the "soft power" of the country. Chinese films 
should, on the basis of paying attention to ethnic customs and national culture, continue to explore the international market and promote Chinese culture so that the achievements of Chinese film art will be recognized and appreciated worldwide. At the same time, Chinese cinema must surpass the purely national customs and comprehensively demonstrate all aspects of social life in China. In particular, it is necessary to look at the living conditions of the present Chinese people and maximize the release of the energy of the cultural spirits carried by Chinese cinema.

\section{References}

[1] Li Xiaoli. Chinese film cross-cultural communication strategy [J]. Contemporary communication. 2010 (03)

[2] Hou Shuangping. TV drama industry cross-cultural communication and cultural infiltration [J]. Consumer Guide. 2009 (02)

[3] Yuan Jin. Globalization and Chinese Imagination - A Study on the Cross-cultural Communication Strategy of Contemporary Films [J]. Journal of Zhejiang Vocational College of Arts and Technology. 2009 (01)

[4] Ning Haoran. Intercultural Communication of Chinese Movies in the Context of Globalization Taking Li An's Family Trilogy as an Example [J]. News World. 2009 (04)

[5] Yang Ying. Analysis of the cross-cultural spread of the film - "Crouching Tiger and Hidden Dragon" and "Red Cliff" as an example [J]. Film Review. 2009 (18)

[6] Su Hongyuan, Li Qi. From the perspective of cross-cultural communication analysis of Hollywood's "Chinese style"[J]. Film Literature. 2009 (12) 